\title{
European analytical column number 46
}

\author{
Wolfgang Buchberger ${ }^{1}$ - Sibel A. Özkan ${ }^{2}$ - Slavica Razic ${ }^{3}$
}

Published online: 30 May 2018

(C) Springer-Verlag GmbH Germany, part of Springer Nature 2018

\section{EuCheMS \\ European Chemical Sciences \\ Division of Analytical Chemistry}

\section{Information from the EuCheMS Division of Analytical Chemistry (DAC)}

Regarding the activities of DAC, the year 2018 may be called "the year between," namely between a highly successful EUROANALYSIS conference held in Stockholm 2017 and another one to be held in Istanbul in 2019. The updated DAC strategy for 2018-2020 approved at last year's annual meeting of DAC defines the promotion of the EUROANALYSIS series of conferences as one of its main themes. Already in 2015 the DAC Steering Committee Members had voted for Istanbul as the venue for EUROANALYSIS XX in 2019. As the name of this conference indicates, the venues are rotated between all European countries, but it was believed that the neighbor countries of Europe should be well integrated into the activities of DAC. Therefore, the Turkish Chemical

Wolfgang Buchberger

wolfgang.buchberger@jku.at

Sibel A. Özkan

ozkan@pharmacy.ankara.edu.tr

Slavica Razic

slavica.razic@pharmacy.bg.ac.rs

1 Institute of Analytical Chemistry, University Linz, Altenbergerstrasse 69, 4040 Linz, Austria

2 Department of Analytical Chemistry, Faculty of Pharmacy, Ankara University, Ankara, Turkey

3 Department of Analytical Chemistry, Faculty of Pharmacy, University of Belgrade, Vojvode Stepe 450, 11222, Belgrade, Serbia
Society will organize this conference in Istanbul (which is often called the bridge between Europe and Asia) from 1 to 5 September 2019 with two chairs, Prof. Dr. Sibel A. Özkan (Ankara University) and Prof. Dr. Mehmet Mahramanlioglu (Istanbul University). The venue will be located in the campus of Istanbul University, which is in the heart of the city center and very close to the road links and public transport.

The detailed information about EUROANALYSIS XX can be found at http://euroanalysis2019.com/. As a broad spectrum conference on analytical chemistry, it will cover all the different topics like "Analytical methods for cultural heritage and art," "Analytical instrumentation," "Biomedical analysis," "Biomolecular analysis," "Biosensors," "Chemical analysis," "Chemometrics," "Clinical chemistry," "Education in analytical chemistry," "Environmental analysis and monitoring," "Food analysis," "Forensic science," "Green analytical chemistry," "Laboratory automation," "Materials science," "Metabolomics," "Nano analysis," "Pesticideresidue analysis," "Pharmaceutical analysis," "Proteomics," "Surface science," and others.

Among the highlights of a EUROANALYSIS conference, one will find the Robert Kellner Lecture, an award to distinguish a person who has made substantial contribution to the advancement of analytical chemistry research or education. Another highlight will be the presentation of the "DAC-EuCheMS Award" for sustained contributions to analytical chemistry in Europe. This award shall distinguish a European individual who has demonstrated significant and sustained achievements in analytical chemistry research or education throughout his/her career. Nominations for the Robert Kellner Lecture and for the DAC-EuCheMS Award are due by 31 October 2018 and should be sent to the Chair or the Secretary of DAC (addresses can be found at http://www. euchems.eu/divisions/analytical-chemistry/).

EUROANALYSIS in Istanbul will be the 20th event within this series of conferences. Over the years, it has become a well-established meeting for the presentation of 
recent advances in analytical chemistry at the highest possible scientific level. Despite the digital revolution encountered during the last years, the personal contacts within the scientific community are still vital. However, recently, the landscape of conferences has changed a bit, and it has not always changed for the better. Suddenly, conferences have been announced with names similar to the established conferences but with quite dubious practices regarding the scientific quality. It becomes obvious that there are companies that take scientific conferences as an opportunity to make profits. You may check Wikipedia for "Predatory conferences" ("....meetings set up to appear like legitimate scientific conferences but which are exploitative as they do not provide proper editorial control over presentations and advertising...”). Contrary to this, EUROANALYSIS has always been and will always be embedded into scientific chemical societies and into DAC as a non-profit organization. The promotion of EUROANALYSIS defined by DAC as one of its main themes guarantees the high scientific standards of this conference.

Other ongoing activities of DAC are performed within study groups. These include "Bioanalytics," "Chemometrics," "Education," "History," "Quality Assurance," and "Nanoanalytics." Please check the DAC website for their reports. In this context, it may be worth mentioning that Sergei Shtykov, Head of the Study Group Nanoanalytics, has recently edited a book "Nanoanalytics: nanoobjects and nanotechnologies in analytical chemistry" containing various interesting contributions to this topic.

DAC also intends to intensify the cooperation with other Divisions of EuCheMS, especially with the Division of Chemistry and the Environment (DCE). At the 17th International Conference on Chemistry and the Environment in Thessaloniki next year, DAC will have a full session dedicated to Analytical Chemistry.

In 2018, one of the main events of EuCheMS will be the 7th EuCheMS Chemistry Congress (26-30 August 2018) in Liverpool with its theme "Molecular frontiers \& global challenges" (https://www.euchems2018.org/). There will be two special sessions dealing with specific aspects of analytical chemistry, namely "ABC of Analytics," organized by Guenter Gauglitz (a member of the Study Group Bioanalytics), and "Pattern Recognition for Chemometrics and Metabolomics," organized by Richard Brereton (a member of the Study Group Chemometrics).

Last, but not least, the current team of the Steering Committee of DAC will be happy to receive input for additional activities. Feel free to contact one of the following persons: Slavica Ražić, University of Belgrade, Serbia (Chair); Marcela Alves Segundo, University of Porto, Portugal (Secretary); Jiri Barek, Charles University, Czech Republic (Treasurer); Charlotta Turner, Lund University, Sweden; Sibel A. Özkan, Ankara University, Turkey; Christian Rolando, University of Lille, France; and Martin Vogel, University of Münster, Germany. 